\title{
Public Perception of Geoengineering
}

\author{
Sylvia Hiller and Ortwin Renn*
}

\begin{abstract}
The paper provides an analysis of the present situation of public perception and develops normative guidance for public debate regarding geoengineering from a social science perspective. The article includes a description of the concerns and perceptions of the general public based on a literature review and a media analysis. It furthermore addresses the prospects for a potential information and communication process in structuring future public debates on geoengineering. Its main target is to provide a protocol for risk managers and regulators on how to address the concerns of the public and how to design more effective risk communication programs.
\end{abstract}

Keywords: Geoengineering, public perception, risk perception Geoengineering, öffentliche Wahrnehmung, Risikowahrnehmung

\section{Introduction}

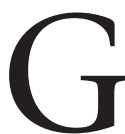
eoengineering is a collective term for "the deliberate large-scale manipulation of the planetary environment to counteract anthropogenic climate change" (The Royal Society 2009: 1). It encompasses technologies designed to remove the causes of climate change (carbon dioxide removal, including $\mathrm{CO}_{2}$ capture and storage, CCS) and to treat the symptoms associated with it (solar radiation management). The prospect of using geoengineering is of major concern to many NGOs and parts of the public. Uncertainty about the potential side effects of geoengineering is one of the most significant factors determining its acceptance by society. Quantifying these risks is difficult, as geoengineering involves major interactions between human interventions and natural phenomena. Gaps in our current state of knowledge make it difficult, if not impossible, to estimate the likelihood of individual geoengineering technologies for causing particular effects, the intensity of those particular effects, and the severity of the damage should these effects occur.

The possibility that application of geoengineering technologies could cause severe damage on a global scale might be reason enough to avoid them, even if the probability of such a disaster occurring is estimated to be extremely low. Analyses of the risks posed by geoengineering technologies have been founded on plausible (but still unverified) assumptions, with most analyses using Bayesian or portfolio approaches and expert best estimates for assessing risks. The perception of these risks by the public and the media is, however, not only influenced by scientific assessments. It is also the product of personal opinions and general attitudes towards risk. Arguments based on ethical considerations or theories of justice must also be taken into account. They are quite likely to be combined with arguments about technical and scientific uncertainty, and in some cultures they may go hand in hand with a general distrust of technology or even of civilization in general.

\footnotetext{
Syvia Hiller is research associate of the Interdisciplinary Research Unit for Risk Governance and Sustainable Technology Development (ZIRN) at the University of Stuttgart and at Dialogik gGmbH, a research institute for the investigation of communication and participation processes in environmental policy making. Dr. Dr. hc Ortwin Renn serves as full professor and chair of environmental sociology and technology assessment at Stuttgart University and is director of ZIRN and Dialogik. This article was peer-reviewed.
}

This article illustrates some central insights from the current theoretical literature about public perception of contested technologies as well as the few but significant empirical investigations about public perception of geoengineering. It also includes the results of a media analysis conducted by the authors. Particular attention is given to the social conflict potential of geoengineering research and the large-scale deployment of geoengineering technologies in the eyes of the public. Based on this analysis, the paper will draw some conclusions for addressing these concerns and perceptions and develop a model design for shaping future public debates on geoengineering.

\section{Social Theories of Risk Perception}

Public perceptions of risk are only marginally determined by the scientifically derived probability of particular outcomes. Psychological studies show that risks of geoengineering are often associated with the pattern of pending danger (Renn 2008; Renn et al. 2007: 21f). Risk in this pattern is seen as a random threat that can trigger a disaster without prior notice and without sufficient time to cope with the hazard involved. This image is linked to artificial risk sources with large catastrophic potential. Risk sources in this category include major facilities like nuclear power plants, liquid natural gas (LNG) storage facilities, chemical production sites and other man-made sources of potential danger which could have catastrophic effects on man and the environment in the event of a serious accident. The impact of this risk class on risk perception depends on three factors:

- the random nature of the event,

- the expected maximum impact, and

- the time-span for risk control measures.

Studies on risk perception show that in these cases the small numerical probability of these random events plays hardly any role for the perceived seriousness of the risk under review: It is the random nature of the event that poses the feeling of threat. Human beings are more comfortable with threats that they can foresee and plan for rather than threats that could materialize themselves at any time regardless of how unlikely 
that might be. The prospect of being exposed to such random effects makes many people feel threatened and powerless.

The debate on geoengineering research and possible deployment of geoengineering technologies also provokes images of big power versus public interests and associations with equity violations. Conflicts over public goods such as the climate are particularly difficult to resolve, as individual stakeholders, including states, have virtually no incentive to provide the collectively desirable outcome on their own. It is therefore necessary for all stakeholders to cooperate with one another (Ostrom et al. 2002; Renn 2010). Furthermore, conflicts over global public goods are characterized by very diverse interests on the part of the stakeholders involved and by cultural and political circumstances. For example, the conflict caused by the search for a suitable location for CCS can be identified as a typical distribution conflict. The public perceives that the distribution of costs and risks is unequal: the risk is borne by a few, while many others, or the community as a whole, reap the benefits (Rosa 1988).

Geoengineering technologies may involve insidious hazards. To cite one example, the use of sulfur to modify the stratosphere may involve globally distributed health risks. Experiences with environmental contamination resulting from human activity (pesticide residues in drinking water, genetic engineering, etc.) reveal that risks of this kind are intuitively perceived to be particularly severe and are often feared more than comparable risks posed by everyday routines or natural sources. For example, the risk of contracting cancer as the result of being exposed to environmental pollution causes greater fear than the risk as the result of smoking cigarettes. This is because people fear invisible risks more than the visible risks. Accordingly, it is in line with human psychology for a person to fear the risks posed by genetically modified food and at the same time to indulge in risky behavior like speeding (Rohrmann and Renn 2000). In assessing risks that are not discernible via the senses, people depend on experts for information. When people do not trust the institutions whose job it is to provide the necessary information, conflicts will result. Most people demand a zero-risk approach if they do not trust those institutions. The risk managers responsible are not trusted to weigh up risks objectively. Accordingly, people are not willing to accept any degree of risk at all for the purpose of achieving a given benefit (Renn 2005). Those who do not trust geoengineering experts will reject any technology they propose, regardless of the actual level of risk involved.

\section{Societal Risk Discourses and Risk Perception in the Social Sciences}

Until now, only a handful of social science studies dealing with geoengineering or climate engineering have been published. Studies outside the domain of the natural sciences still focus mainly on areas like international relations, governance, ethics, and economic analysis, although current research projects at Heidelberg's Marsilius Kolleg Advanced Research Center do conduct projects involving a sociological perspective. The few existing social science studies on geoengineering mainly consist of articles weighing up the pros and cons of geoengineering on the basis of theoretical considerations or arguments derived from analogies with other sectors of technology. They also examine the resonance of such arguments in the political sphere and among the wider public. It is generally assumed that public acceptability problems associated with radiation management technologies, in particular, might actually prevent them from materializing, but some carbon dioxide removal technologies would also be affected. Jackson and Salzman (2010) doubt whether the public will ever accept radiation management technologies as reflectors in space and the spreading of nanoparticles in the stratosphere, or carbon dioxide removal technologies such as ocean fertilization. They recommend forest protection and afforestation, the industrial capture of $\mathrm{CO}_{2}$, and the use of bioenergy in combination with CCS as alternative options. But they also remark that actual cases in the Netherlands and Germany indicate that major public opposition to CCS must be reckoned with. Their conclusion is that the geoengineering debate should focus on the technologies with the best chances of being accepted by the public (Jackson and Salzman 2010).

The assumption widely held in the current literature is that the factors most strongly supporting the protest against geoengineering technologies are (i) concerns about the impossibility of estimating the risks involved and (ii) ethical, legal, governance-related, and geopolitical concerns. Related to the risks involved, a number of potential risk areas have been identified, ranging from the mere preparation of geoengineering experiments to the political realization of geoengineering technologies, the impact of geoengineering on political stability, the possible interruption of geoengineering deployment, and the misuse of the geoengineering technologies (Grunwald 2010; Scheer and Renn 2010; Corner and Pidgeon 2010). In the context of the political realization of geoengineering technologies and its impact on political stability, the unilateral deployment of these technologies is perceived as particularly critical and potentially disastrous in its consequences (Corner and Pidgeon 2010). It follows that the acceptance of these technologies by the public will depend not only on how risks are perceived, but also on how much trust in the regulatory institutions is involved, on how transparent geoengineering activities appear, and how much confidence exists in the nature of the liability regimes (Jackson and Salzman 2010; Bracmort et al. 2010).

Furthermore, potential physical health issues and psychological problems complicate the acceptance of geoengineering technologies. The latter might materialize if radiation management deployment caused more vibrant sunsets or duller skies (Scheer and Renn 2010). Moreover, concerns that the prospect of geoengineering deployment might undermine sensitivity to the need for sustainable patterns of production and consumption are a crucial factor for public acceptance. Furthermore, these concerns are not restricted to actual deployment; it has also been asserted that mere geoengineering research itself might be enough to undermine other efforts undertaken to avoid climate change. This state of affairs might also be exacerbated by lobby groups who have no interest in reducing emissions (Corner and Pidgeon 2010). However, 
studies also reveal that the opposite might be the case. Low acceptance of geoengineering technologies or fears that these technologies could actually be deployed might also step up efforts to reduce emissions. Geoengineering would effectively act as a catalyst for a form of social engineering, a process that would be open to criticism on moral grounds (Corner and Pidgeon 2010).

Research of the Royal Society has yielded interesting results on the topic of acceptance and public dialogue. The report includes results of a preliminary study based on discussions between focus groups representing various public attitudes to geoengineering. The focus groups were stratified in terms of environmental beliefs and behaviors and discussed potential risks, benefits, and areas of uncertainty in relation to various geoengineering technologies (The Royal Society 2009: 43). The study revealed that the perceptions of geoengineering among the focus groups were largely negative. In the light of these results, the Royal Society recommends that further and more thorough investigations of public attitudes, concerns, and uncertainty as regards geoengineering be conducted, parallel to technological research and development work and a public dialogue with citizens. Similar recommendations can also be found in other publications. The American Meteorological Society, for example, has recommended that the scientific and technical exploration of the potential of geoengineering technologies should be accompanied by broadly based studies of their social and ethical implications (AMS 2009).

The acceptance problems arising in connection with CCS demonstrate the necessity of involving stakeholders and affected citizens at an early stage (Schulz et al. 2010; Bracmort et al. 2010; Corner and Pidgeon 2010). Such involvement would not only generate acceptance, it would also help in assessing the degree of tolerance present and in pinpointing potential sources of controversy between those who bear more than their fair share of the risks and those who stand to benefit (Schulz et al. 2010). This would call for a dialogue between scientists and academics, political decision-makers and the general public (Bracmort et al. 2010). An international public dialogue in the form of a direct participative model should be initiated as rapidly as possible, before the initiation of largescale geoengineering experiments is even considered. The public should play an active advisory role throughout the period during which scientific research and development is going on and, even more importantly, before any significant geoengineering intervention materializes that is driven by commercial interests. Deliberative workshops (similar to focus groups) and citizens' juries (similar to planning cells, with a panel of citizens selected on the basis of certain criteria to represent the fundamental spectrum of opinions and attitudes present in the population) have been recommended as formats facilitating such participation (Corner and Pidgeon 2010).

A dialogue of this kind must be informed by an awareness that risk cultures and world views vary. Attitudes towards the deployment of technologies such as genetic engineering may differ from one country to the next (Scheer and Renn 2010; Corner and Pidgeon 2010). It is also important to evaluate individual geoengineering technologies in order to determine the scale of the opportunities and risks they pose, the extent to which the public trusts the science involved, and the effects of the technologies on social justice, as these technologies are part of a broader strategy designed to mitigate anthropogenic climate change (Jackson and Salzman 2010).

\section{Empirical Results on Public Perception}

Taking the number of published media articles as an indicator, it becomes evident that geoengineering has reached an increasingly wide audience in English-speaking countries in the last two years. In parallel with the media echo, scientific and political interest in geoengineering is gradually increasing. The overall attitude towards geonengineering is mixed: positive visions compete with more skeptical and outright negative evaluations. In contrast to the UK and the US, the interest of the media in the topic geoengineering has been much less pronounced in Germany. Furthermore, the main emphasis in the German media is to raise warning signs und convey a skeptical and apprehensive vision of its future. Reports with a clearly positive outlook are rare. These insights are a result of a media analysis by the authors evaluating over 40 international media articles from 2008 to 2010 both categorically and quantitatively. An analysis of readers' comments and letters in online articles and blogs supported these insights: similar to the media reporting, they tend to be critical or negative.

Even though geoengineering has been discussed more intensively and longer in the USA than in Germany, US surveys have shown that 74 percent of those questioned have never heard of geoengineering and only 3 percent had a realistic idea of what it actually is (Leiserowitz 2010). Representative figures are not yet available for Germany. From the few studies available, it is fair to assume that the majority of the German population currently either have no opinion on geoengineering or view it with caution and skepticism, as mirrored by the German media. Similar results were obtained when looking at public perception of CCS (Schulz et al. 2010). Here again, knowledge of the CCS technology among the general public is limited, but the majority of those who have already formed an opinion are opposed to its use. Furthermore, it is likely that increasing media coverage, especially relating to the risks and the moral hazards implicit in geoengineering technologies, will lead to increased skepticism about, and hostility toward geoengineering. The controversial discussion on the LOHAFEX project has already provided evidence for this claim, albeit on a small scale relating to the method of iron fertilization of oceans. The debate and the attitudes of those involved were influenced by critical opinions and opposition to the project voiced online.

As mentioned before, the focus groups of the Royal Society showed that attitudes towards geoengineering technologies in Britain are also predominantly negative, although acceptance varied dramatically among the participants. The reasons for concern referred to were very diverse and closely geared to the precise technology under consideration. Some of those questioned, for example, had fundamental ethical objections to all forms of geoengineering, while others had none. In addition, a small-scale telephone survey involving 1,000 
participants was conducted on behalf of the Royal Society. Responses to this survey were particularly negative whenever the interviewers touched on technologies for the modification of the stratosphere. 47 percent were opposed to the deployment of such technologies. Another 39 percent rejected ocean iron fertilization (The Royal Society 2009: 43).

Studies carried out by the International Risk Governance Council (IRGC 2006) and the National Environmental Research Council (NERC 2010) show that solar radiation management technologies engender more controversy than carbon dioxide removal technologies, because they would have global effects and cannot be deployed in a manner that would only affect specific regions. The fact that radiation management technologies only tackle the symptoms and do not get to the root of the matter is also seen as a problem. In addition to their potential risks for the environment, the evaluation of geoengineering technologies must also be based on controllability, deployment reversibility plus consequences, cost-effectiveness, whether technologies can be brought on stream in time or not, and fair regulation of the field of operation.

In contrast, most of those questioned in the above surveys were in favor of afforestation and the production of biochar coal, as these tended to be seen as what are often called noregret measures that would bring other advantages besides climate protection. Methods involving the ocean, such as iron fertilization, were seen as particularly risky with regard to their effects on ecosystems. Participants were in favor of combining various international geoengineering technologies with individual, national and international efforts to control emissions. In general, adopting sustainable lifestyles was seen as the only possible long-term solution. The results of the public dialogue initiated by NERC suggest that a majority of the population is not opposed to geoengineering in principle, but deeply concerned about the implications of deploying particular technologies (NERC 2010). Otherwise, opinions on climate change are strongly influenced by the degree to which those questioned perceive climate change to be a serious problem and by how successful they judge emission control efforts to be.

Geoengineering technologies are often seen as a substitute for emission abatement, which reduces its acceptance. While economic analysis does show that such substitution is possible under certain circumstances (Klepper and Rickels 2011), the Royal Society (2009) also points out that the prospect of geoengineering deployment might sharpen sensitivities for the problem that emissions represent and lead to a redoubling of efforts to avoid them. A number of participants in the Royal Society focus groups were skeptical about climate change and either reluctant to embrace geoengineering technologies or hostile to them. They stated that planned investments in geoengineering technologies and measures had motivated them to act in a more climate-friendly manner (reducing their own emissions, etc.) so as to avert the necessity for geoengineering in future. Corner and Pidgeon (2010: 31) also highlight the current uncertainty about whether and how strongly negative feedback leads to emission abatement. They suggest that representatives from the social sciences should do research to find out how the geoengineering debate influences attitudes towards climate change and individual behavior. While the moral hazard phenomenon has been statistically demonstrated in conjunction with other technical innovations, such as the introduction of seat belts in vehicles, no empirical evidence supporting the moral hazard argument in a geoengineering context has yet materialized. The Royal Society study highlights three particular aspects that might lead to greater acceptance: (i) transparency about actions, motives, and aims, (ii) absence of commercial lobbies, and (iii) demonstrable interest in, and responsibility for, effects on the environment.

Deliberative workshops held in the UK and Portugal by the European project Deepening Ethical Engagement and Participation in Emerging Nanotechnologies (DEEPEN) have identified five key positions often associated with nanotechnology. As there are striking parallels between the development of nanotechnology and of geoengineering, these key positions suggest views that may be advanced in public in the future on geoengineering (Davies et al. 2009):

- "Be careful what you wish for": getting exactly what you want may not ultimately be the ideal outcome.

- "Opening Pandora's box": interventions in the complex Earth system may lead to disaster.

- "Messing with nature": redesigning nature so that it more closely suits with our needs occasions moral scruples about destroying the existing order of the natural world.

- "Kept in the dark": geoengineering measures should be rejected until decision-makers stop leaving the public in the dark about important aspects of the technology and its side effects.

- "The rich get richer and the poor get poorer": geoengineering might exacerbate existing inequalities and injustices.

Interestingly, participants in the project tended to reject a vision that technology will continue to advance and will inevitable bring progress to human society. Although participants were given background information from the hard sciences, the societal and ethical effects were the central topic of discussion. Based on analogies to other technologyassociated controversies, it cannot be expected that social acceptance would be higher if the geoengineering debate were restricted to geoengineering research involving field testing as opposed to a decision on large-scale and long-term geoengineering deployment. This has become evident, for example, in connection with CCS research in Germany. The protest movement in Brandenburg, to mention just one, has protested vigorously against the testing of CCS (Schulz et al. 2010).

\section{Comparisons with other Technology Discourses}

So far studies about public perception of geoengineering do not allow to draw a conclusion about how the debate will evolve in Germany. Insights derived by drawing parallels with other technologies may give some indication of how the 
population is likely to react to geoengineering. We have asked experts, who have analyzed previous technology debates, to compare the geoengineering controversy with the debates and their attendant conflicts that they have studied, e.g. genetic engineering, nuclear energy, waste incineration (Renn et al. 2011: 43):

- For the modification of the stratosphere, clear parallels with nuclear energy were drawn, principally because of the fact that the effects span generations.

- For ocean fertilization, parallels with debates over organic agriculture and genetic engineering were drawn, as effects could be expected on biodiversity and ecology.

- For afforestation, parallels were drawn with anti-flooding measures, the designation of flood overflow areas, and general conflicts over land use.

The most fruitful comparisons can be drawn by looking at the history of the acceptance problems caused by the implementation of nuclear installations, genetic engineering, and nanotechnology. All these technologies have in common that the opportunities were presented first, with a degree of euphoria, while the risks were either neglected or downplayed. For all these reasons, it seems unrealistic to expect a comprehensive consensus about geoengineering.

\section{Recommendations for Information and Discourse Strategies}

Based on the current literature as well as on the case studies from similar technological debates, it can be concluded that at this early stage in the development of geoengineering it is necessary to provide the public with sufficient information about the topic. A comprehensive communication program should treat geoengineering technologies in the light of the wider debate on climate change, emission control and adaptation. Guided by the precautionary principle, a communication program could focus more on the potential risks of geoengineering than on explaining technical details of geoengineering. Together with sufficient information on opportunities and risks, the level of uncertainty involved should also be highlighted as a central issue of communication.

Dialogue with the public should keep pace with scientific research on the advantages and disadvantages of geoengineering technologies. In this way, it would be possible to keep track of the current debate about the acceptability of side effects in the light of the latest research and to evaluate geoengineering technologies as one option among many comprehensive climate protection policies. We suggest that a three-stage plan be used to integrate citizen participation in this process:

1. Provision of extensive information and communication via the Internet and through public institutions active in the wider context of the climate change debate.

2. Organization of round tables or forums with stakeholders to identify the interests and preferences of organized groups in matters relating to geoengineering research and deployment.
3. Organization of (web-based) citizens' forums or citizens' conferences to assemble information on the wishes, concerns, and ideas of citizens who are not affiliated with specific organizations and to feed this information back into the formulation of policy.

When and if concrete geoengineering deployments are considered in the future, specific round tables or other formats should be used to convey informed preferences to decisionmakers.

Knowledge, attitudes, and mobilization potential should be systematically recorded at regular intervals. The background conditions and the priorities set by actors must be understood better as they progress over time and in the complex, dynamic context of opinion-formation and mobilization mechanisms. For that reason, the interplay between the parameters of information reception, understanding of risk and uncertainty should be investigated in order to gain a clear idea of (i) the degree to which consensus is possible, (ii) where the opportunities for participating in deliberative decision-making on geoengineering technologies actually lie, and (iii) what restrictions exist on participation.

\section{References}

AMS (American Meteorological Society) (2009): Policy Statement on Geoengineering the Climate System. AMS. Boston. http://www.ametsoc.org/policy/2009geoengineering climate_amsstatement.pdf

Bracmort, Kelsi / Lattanzio, Richard K. / Barour, Emily C. (2010): Geoengineering: Governance and Technology Policy. Congressional Research Service (Ed.): CRS Report for Congress (Library of Congress, Washington/D.C.). http://fpc.state.gov/ documents/organization/147294.pdf .

Corner, Adam / Pidgeon, Nick (2010): Geoengineering the Climate: The Social and Ethical Implications. Environment, Vol. 52, Issue 1. Pp. 24-37.

Davies, Sarah / Macnaghten, Phil / Kearnes, Matthew (2009): Reconfiguring Responsibility: Deepening Debate on Nanotechnology. A Research Report from the DEEPEN Project.

http://www.geography.dur.ac.uk/Projects/Portals/88/ Publications/Reconfiguring\%20Responsibility\%20 September\%202009.pdf.

Grunwald, Armin (2010): Der Einsatz steigt: globale Risiken. Karlsruher Institut für Technologie -KIT-, Institut für Technikfolgenabschätzung und Systemanalyse -ITAS-, Politische Ökologie, No. 120. Pp. 37-39.

IRGC (International Risk Governance Council) (2006): White Paper on Risk Governance Towards an Integrative Approach. IRGC. Genf.

Jackson, Robert B. / Salzman, James (2010): Pursuing Geoengineering for Atmospheric Restoration. Issues in Science \& Technology, 2010, Vol. 26, Issue 4. Pp. 67-76. 
Klepper, Gernot / Rickels, Wilfried (2011): Climate Engineering Wirtschaftliche Aspekte. Kiel Earth Institute/BMBF. Kiel/ Berlin. http://www.kiel-earth-institute.de/projekte/forschung/ okonomie.

Leiserowitz, Anthony (2010): Geoengineering and Climate Change in the Public Mind. Presentation to the Asilomar International Conference on Climate Intervention Technologies, Pacific Grove, CA, 24 March 2010.

NERC (Natural Environmental Research Council) (2010): Experiment Earth? Report on a Public Dialogue on Geoengineering. August 2010. National Academy Press. Washington, D.C.

http://www.nerc.ac.uk/about/consult/geoengineeringdialogue-final-report.pdf.

Ostrom, Elinor / Dolsak, Nives / Stern, Paul C. / Stonich, Susan / Weber, E.U. (2002): The Drama of the Commons. National Academy Press. Washington, D.C.

Renn, Ortwin (2010): The Contribution of Different Types of Knowledge Towards Understanding, Sharing and Communicating Risk Concepts. Catalan Journal of Communication \& Cultural Studies, Vol. 2, No. 2. Pp. 177-195.

Renn, Ortwinn (2008): Risk Governance. Coping with Uncertainty in a Complex World. Earthscan. London.

Renn, Ortwin (2005): Risk Perception and Communication: Lessons for the Food and Food Packaging Industry. Food Additives and Contaminants, 22, No. 10. Pp. 1061-1071.

Renn, Ortwin / Brachatzek, Nadine / Hiller, Sylvia (2011): Risikowahrnehmung, gesellschaftliche Risikodiskurse und Optionen der Öffentlichkeitsbeteiligung. Dialogik/BMBF. Stuttgart/Berlin. http://www.kiel-earth-institute.de/projekte/forschung/ gesellschaftsstudie

Renn, Ortwin / Dreyer, Marion (2010): Vom Risikomanagement zu Risk Governance: Neue Steuerungsmodelle zur Handhabung komplexer Risiken. In: Münkler, H. / Bohlender, M. / Meurer, S. (Eds.): Handeln unter Risiko. Gestaltungsansätze zwischen Wagnis und Vorsorge. Pp. 65-82. transcript. Bielefeld.

Renn, Ortwin / Schweizer, Pia-Johanna / Dreyer, Marion / Klinke, Andreas (2007): Risiko. Über den gesellschaftlichen Umgang mit Unsicherheit. Oekom. München.

Rohrmann, Bernd / Renn, Ortwin (2000): Risk Perception Research - An Introduction. In: Renn, O. / Rohrmann, B. (Hrsg.): Cross-Cultural Risk Perception. A Survey of Empirical Studies (pp. 11-54). Kluwer Academic Publishers. Dordrecht/ Boston.

Rosa, Eugene A. (1988): NAMBY PAMBY and NIMBY PIMBY: Public Issues in the Siting of Hazardous Waste Facilities. Forum for Applied Research and Public Policy, Vol. 3. Pp. 114-123.

Royal Society (2009): Geoengineering the Climate: Science, Governance and Uncertainty. September 2009, RS Policy document 10/09. London. http://eprints.soton.ac.uk/156647/1/ Geoengineering_the_climate.pdf.

Scheer, Dirk / Renn, Ortwin (2010): Klar ist nur die Unklarheit: die sozio-ökologischen Dimensionen des Geo-Engineering. Politische Ökologie, No. 120. Pp. 27-29.

Schulz, Marlen / Scheer, Dirk / Wassermann, Sandra (2010): Neue Technik, alte Pfade? Zur Akzeptanz der $\mathrm{CO}_{2}$ Speicherung in Deutschland. GAIA, Vol. 19, No. 4. Pp. 287-296.

Sjöberg, Lennart (2008): Antagonism, Trust and Perceived Risk. Risk Management, Vol. 10. Pp. 32-55.

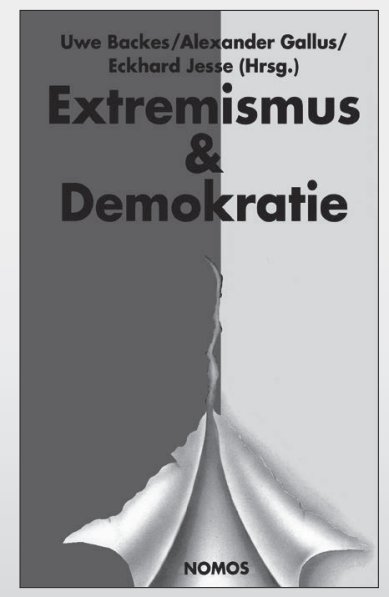

Weitere Informationen: www.nomos-shop.de/20002

\section{Jahrbuch Extremismus \& Demokratie (E \& D) \\ 24. Jahrgang 2012 \\ Herausgegeben von Uwe Backes, Alexander Gallus und Eckhard Jesse \\ 2012, 534 S., geb., 54,- €, ISBN 978-3-8329-7999-7}

Band 24 des Jahrbuches gliedert sich wie jedes Jahrbuch zuvor in die bewährten drei Rubriken „Analysen“, „Daten, Dokumente, Dossiers“ und „Literatur“. Die Entwicklung im politischen Extremismus wird nachgezeichnet - vor allem im Jahr 2011 und vor allem in Deutschland, aber auch darüber hinaus. 